\title{
Year-Dependent Change of DNP Parameters in p-Difluorobenzene Suspension with Asphaltene
}

\author{
Handan ENGIN KIRIMLI* \\ Bursa Uludag University, Sciences and Arts Faculty, Physics Departments, Bursa, Turkey \\ (ORCID: 0000-0003-0300-3381)
}

\begin{abstract}
Petroleum asphaltenes are the heaviest, most aromatic and most complex component of crude oil and asphaltenes are paramagnetic. Overhauser Dynamic nuclear polarization (ODNP) were performed to study samples of asphaltene/p-Difluorobenzene at $1.53 \mathrm{mT}$. p-difluorobenzen solvent with asfalten in three different concentrations waiting five years with oxygen removed have been stuied. Dynamic nuclear polarization parameters were determined by performing ODNP experiments again. The results of our studies and the calculated parameters, especially the coupling parameter, indicates that there were dipolar interactions between nuclei and free electron spins. These dipolar interactions indicate that, at the end of five years the the asphaltene micelles in suspension agglomerated and that make the molecule movements slower. The obtained dynamic nuclear polarization parameters were compared with their values in the literature and it was observed that the parameters decreased slightly with time.
\end{abstract}

Keywords: DNP, Overhauser Effect, Asphaltene, Sample Age.

\section{Asfaltenli p-Diflorobenzen Süspansiyonunda DNP Parametrelerinin Yıla Bağlı Değişimi}

\begin{abstract}
$\ddot{O} \mathbf{z}$
Petrol asfaltenleri ham petrolün en ağır, en aromatik ve en kompleks bileşenidir ve asfaltenler paramanyetiktir. Overhauser Dinamik nükleer polarizasyon (ODNP), $1.53 \mathrm{mT}$ da asfalten/p-Diflorobenzen örneklerini incelemek için gerçekleştirildi. Oksijenden uzaklaştırılarak beş yıl bekletilen asfaltenli p-difluorobenzen çözgen üç farklı konsantrasyonda çalışldı. ODNP deneyleri tekrar yapılarak, Dinamik nükleer polarizasyon parametreleri belirlendi. Çalışmalarımızın sonuçları ve hesaplanan parametreler, özellikle çiftlenme parametresi, çekirdek ve serbest elektron spinleri arasında dipolar etkileşmeler olduğunu göstermektedir. Bu dipolar etkileşmeler, beş yılın sonunda süspansiyondaki asfalten misellerinin topaklandığını ve molekül hareketlerini yavaşlattığını göstermektedir. Elde edilen dinamik nükleer polarizasyon parametreleri literatürdeki değerleri ile karşılaştırılmış ve parametrelerin zamanla bir miktar azaldığı görülmüştür.
\end{abstract}

Anahtar kelimeler: DNP, Overhauser Etkisi, Asfalten, Örnek Yaşı.

\section{Introduction}

Asphaltenes are important components of crude oils and bitumens, and they have an amorphous structure. There is no exact chemical formula and molecular weight for asphaltene [1-3]. Nowadays, It enables analytical studies, including magnetic resonance studies of crude oil, which is a center of interest for science and industry [4].

Electron spin resonance experiments performed by many researchers show that asphaltenes are paramagnetic [4-6]. Free radical occurs due to incomplete carbon bonds in the dense aromatic structure of asphaltene particles. That is, free electrons occur due to incomplete carbon bonds. DNP in asphalt suspensions, first performed by Poindexter [7] in a weak constant magnetic field.

"Corresponding author: hengin@uludag.edu.tr

Received: 29.01.2021, Accepted: 30.04.2021 
Dynamic nuclear polarization (DNP) has recently received great attention for its ability to increase signal densities by several times of magnitude in nuclear magnetic resonance (NMR) experiments. DNP, a technique well known in paramagnetic solutions and suspensions, depends on the movement of molecules containing nuclei and free electron spins. This technique, is becoming more and more popular as it magnifies nuclear spin polarization. That is a useful technique in determining asphaltene molecular dynamics and structure of asphaltene. In the case of Overhause DNP, It is a pair of magnetic resonance technique in which nuclear magnetic resonance is observed at the moment when the electron resonance of a paramagnetic substance with which a substance interacts simultaneously is observed. In solution-state, nuclear polarization increas by the methods of Overhauser DNP based on the effect of transfer the polarization from electronic spins to a system of nuclear spins. In our study, the nuclear spins are proton spins, which are the nuclei of the hydrogen atom in the solvent molecule. The Electron spins belong to the intense aromatic structure of asphaltene micelles, unpaired electron delocalized at incomplete carbon bonds. Asphaltenes, which are a mixture of complex molecules, are often a colloidal system with paramagnetic parts in itself [8].

ODNP technique was used to examine asphaltene/p-Difluorobenzene samples at $1.53 \mathrm{mT}$. In this method, intermolecular spin spin interactions occur between the nuclear spins in the diffused solvent molecules and the unpaired electron spins in the asphaltene [9]. The goal of this study is to examine the DNP parameters by doing a similar study (with the DNP technique) for the asphaltene / pdifluorobenzene sample prepared previously, and to examine the year-dependent change on DNP parameters in asphaltene suspensions by comparing with the results five years ago.

Experimental application of ODNP and its theory can be provided in literature [5, 10, 11]. Including the observed nuclear polarizations, $\mathrm{P}_{\mathrm{z}}$, the thermal equilibrium values, $\mathrm{P}_{0}$; the Overhauser DNP enhancement factor is given by [12-14].

$$
E=\frac{P_{Z}}{P_{0}}=1-\rho f s\left|\frac{\gamma_{e}}{\gamma_{n}}\right|
$$

where, $\gamma_{\mathrm{e}}$ and $\gamma_{\mathrm{n}}$, are the gyromagnetic ratios of the electron and nuclear spins, respectively. The leakage factor $f$, the saturation factor $s$ when the ESR is at full saturation, it becomes equal to 1 . The nuclearelectron coupling parameter $\rho$, in the white spectrum approach, is +0.5 for pure dipolar interaction and -1 for pure scalar coupling. The $\rho$ values obtained vary between the limit values of +0.5 and -1 .

When being complete EPR saturation $(s=1)$, the inverse of $E$ factor is extrapolated for the infinite ESR power is derived as

$$
\left(\frac{P_{z}-P_{0}}{P_{0}}\right)_{s \rightarrow 1}^{-1}=-\left(\rho f\left|\frac{\gamma_{e}}{\gamma_{n}}\right|\right)^{-1}=E_{\infty}^{-1} .
$$

For infinite electron spin concentration, $f$ goes to one, from there the ultimate enhancement factor $\left(U_{\infty}\right)$ is reached.

$$
\left(E_{\infty}^{-1}\right)_{f \rightarrow 1, c \rightarrow \infty} \rightarrow\left(-\rho\left|\frac{\gamma_{e}}{\gamma_{n}}\right|^{-1}=U_{\infty}^{-1}\right.
$$

$\rho$ parameter is calculated (for ${ }^{1} \mathrm{H} ;\left|\gamma_{\mathrm{e}} / \gamma_{\mathrm{n}}\right|=658$ ) with

$$
\rho=-U_{\infty} / 658
$$

The importance on dependent scalar coupling is $K$ parameter. Since $\rho$ is an experimentally obtainable parameter, the parameter $K$ can be easily calculated.

$$
K=\frac{1-2 \rho}{1+\rho}
$$




\section{Material and Methods}

MC-800 liquid petroleum asphalt was taken from the Tupras, Refinery in Kirikkale, Turkey. This asphaltane obtained from asphalt and it has a paramagnetic feature. p-difluorobenzene was purchased from Aldrich Chemical Co. (USA). Basic constants and NMR sensitivity of p-difluorobenzene, molecular weight; $114.09 \mathrm{~g} / \mathrm{mol}$, boiling point; $88-89{ }^{\circ} \mathrm{C}$, melting point; $-13{ }^{\circ} \mathrm{C}$, density; $1.170 \mathrm{~g} / \mathrm{cm}^{3}$, and calculated NMR sensitivity; $1.24 \times 10^{22} \mathrm{spin} / \mathrm{cm}^{3}$, respectively.

The suspensions had been prepared before in 2015 in three different asphaltene concentrations. These concentrations are $1.8 \mathrm{~kg} / \mathrm{m}^{3}, 3.3 \mathrm{~kg} / \mathrm{m}^{3}$ and $6.2 \mathrm{~kg} / \mathrm{m}^{3}$, respectively. The presence of oxygen affects the enhancement factor. Degassing treatment should be performed in order to minimize the interactions with air molecules, to take the EPR line to easy saturation and to ensure the long life of the sample. Degassing process was performed in Leybold-Heraeus vacuum system at $10 \mathrm{~Pa}$ pressure value. The prepared samples were kept for 5 years in a closed environment with a temperature range of $4-8{ }^{\circ} \mathrm{C}$.

DNP measurements were fulfill at $1.53 \mathrm{mT}$ fixed magnetic field NMR spectrometer. The spectrometer is hand-made and has a resonance frequency of $61.2 \mathrm{kHz}$ for protons and $43.8 \mathrm{MHz}$ for electrons. The spectrometer was explained in the previous articles [15].

\section{Results and Discussion}

For each sample, $E_{\infty}$ values were determined by extrapolating from the optimal fit lines drawn by obtaining the inverse of the enhancement factors as a function of the inverse of the square of the high frequency voltage, which is proportional to the inverse of the ESR power. The $E_{\infty}{ }^{-1}$ values correspond to the intersection points of the extrapolated optimal fit lines passing through the experimentally obtained points with the line $\mathrm{V}_{\text {eff }}^{-2}=0$ (Figure1).

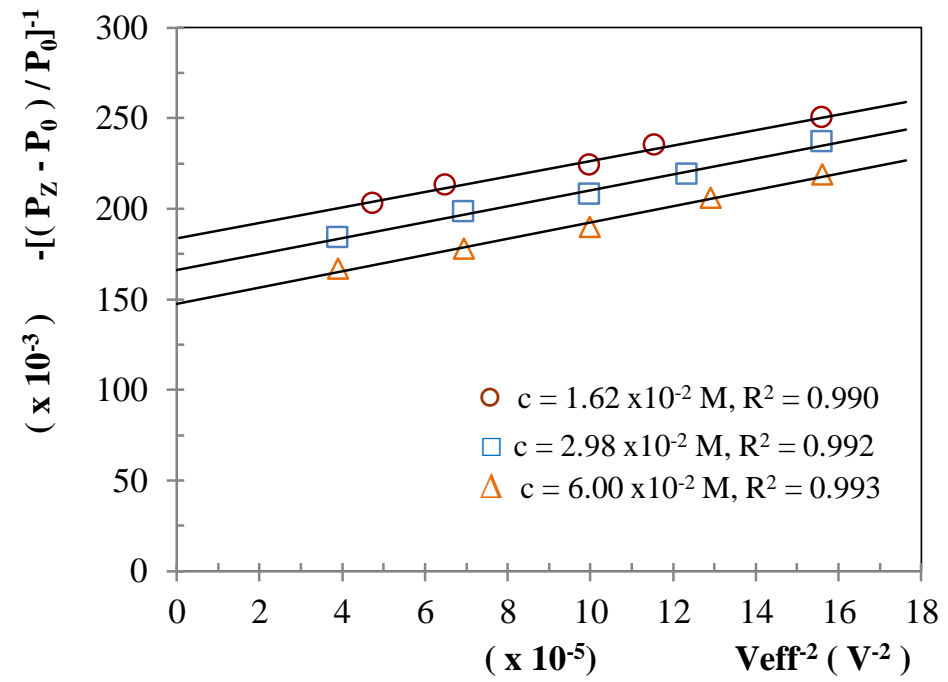

Figure 1. Obtaining $E_{\infty}$ for asphaltene/p-difluorobenzene sample. The $\mathrm{R}^{2}$ values indicate the regression of the experement points.

The ultimate enhancement factor $U_{\infty}$ was determined by extrapolating to the infinite concentration from the optimal fit lines drawn to the $E_{\infty}$ values found for that medium as a function of the inverse of the concentration. The $U_{\infty}{ }^{-1}$ value corresponds to the point of intersection of the extrapolated optimal fit line passing through the obtained points with the line $c^{-1}=0$ (Figure 2). 


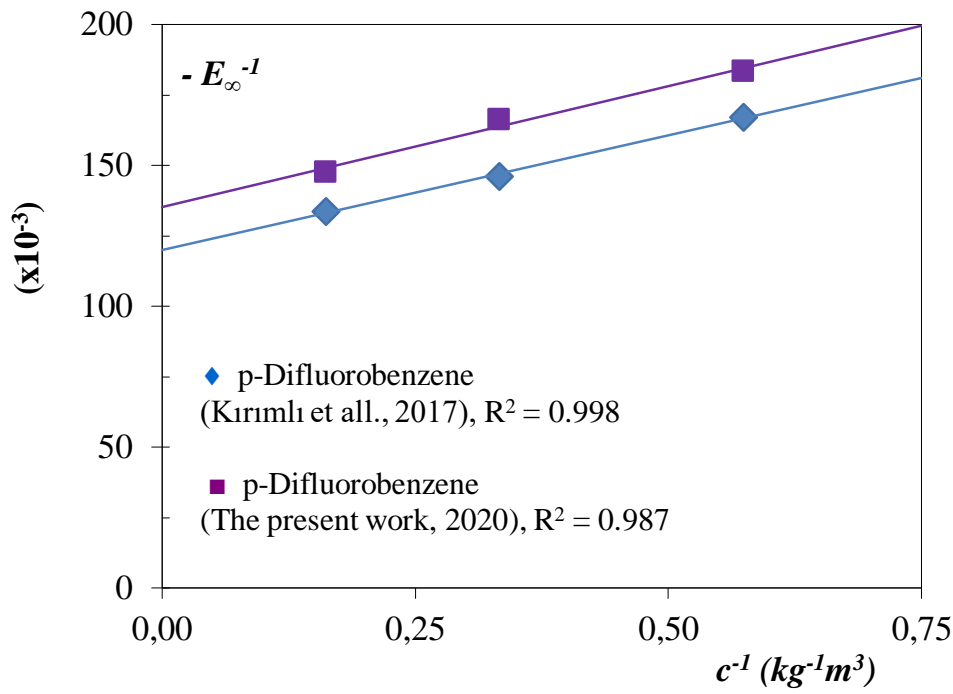

Figure 2. Obtaining $U_{\infty}$ for asphaltene/p-difluorobenzene sample at three different concentrations.

After $\rho$ value calculated from equation (4), $K$ value can be found by equation (5). The DNP parameters obtained for the asphaltene/p-difluorobenzene sample, $E_{\infty}, E_{e n d}, U_{\infty}, \rho, f, s, K$ are presented in Table 1. As seen in Table 1, all the $E_{\infty}$ values are negative, these values vary between -6.8 and -5.4. This is due to the inversely enhancement of the signal. This situation indicates that the interaction between the nuclear spins and electron spins is dipolar. After the DNP experiments of the samples prepared in 2015 were carried out, the DNP experiments of the same samples were repeated in 2020.

Table 1. The DNP parameters $\left(E_{\infty}, E_{\text {end }}, U_{\infty}, \rho, s, f, K\right)$.

( $E_{\text {end }}$, the enhancement factor for maximum available the EPR power)

\begin{tabular}{lcccccccc}
\hline & $c\left(k g m^{-3}\right)$ & $E_{\infty}$ & $E_{\text {end }}$ & $U_{\infty}$ & $\rho$ & $\begin{array}{c}f \\
\left(E_{\infty} / U_{\infty}\right)\end{array}$ & $\left(E_{\text {end }} / E_{\infty}\right)$ & $K$ \\
\hline The present & 1.8 & -5.4 & 5.0 & & & 0.730 & 0.926 & \\
work (2020) & 3.3 & -6.0 & 5.4 & 7.4 & 0.011 & 0.811 & 0.901 & 0.967 \\
& 6.2 & -6.8 & 6.0 & & & 0.919 & 0.882 & \\
& & & & & & & & \\
Kirimli et al. & 1.8 & -6.0 & - & & & 0.718 & 0.833 & \\
[8] & 3.3 & -6.8 & - & 8.3 & 0.013 & 0.820 & 0.891 & 0.962 \\
& 6.2 & -7.5 & - & & & 0.898 & 0.889 & \\
\hline
\end{tabular}

\section{Conclusions}

The $\rho$ value can vary from -1 in the case of pure scalar coupling to +0.5 in the case of pure dipolar coupling. The results of our studies and the calculated parameters, especially the coupling parameter, indicates that there were dipolar interactions between the nuclear spin and the electron spin. This conclusion is also supported by the parameter $K$.

The obtained dynamic nuclear polarization parameters were compared with their values in the literature and it was observed that the parameters decreased slightly with time. When the values obtained from this study and the $\rho$ values obtained by Kirimli [8] are compared and the percentage change is examined, it is seen that the decrease is $10.8 \%$.

These dipolar interactions indicate that, at the end of five years the the asphaltene micelles in suspension agglomerated and that make the molecule movements slower. In addition, it is seen that the asphaltene micelles are aggregated to a greater extent and the interaction for this reason is reduced.

\section{Author's Contributions}

All contributions belong to the author in this paper. 


\section{Statement of Conflicts of Interest}

The author has no conflict of interest regarding this article.

\section{Statement of Research and Publication Ethics}

The author declares that this study complies with Research and Publication Ethics.

\section{References}

[1] Headen T.F., Boek E.S., Skipper N.T. 2009. Evidence for Asphaltene Nanoaggregation in Toluene and Heptane from Molecular Dynamics Simulations. Energy Fuels, 23: 1220-1229.

[2] Liu J., Zhao Y., Ren S. 2015. Molecular Dynamics Simulation of Self-Aggregation of Asphaltenes at an Oil/Water Interface: Formation and Destruction of the Asphaltene Protective Film. Energy Fuels, 29: 1233-1242.

[3] Aydogdu D, Cimenoglu M.A, Yalciner A. 2006. Dynamic Nuclear Polarization in Suspensions Consisting of Xylene Isomers and Asphaltene Extracted from MC-800 Liquid Asphalt. Journal of Dispersion Science and Technology, 27: 955-961.

[4] Gizatullin B., Gafurov M., Rodionov A., Mamin G., Mattea C., Stapf S., Orlinskii S. 2018. Proton-Radical Interaction in Crude Oil-A Combined NMR and EPR Study. Energy Fuels, 32: 11261-11268.

[5] Gutowsky H.S., Ray B.R., Rutledge R.L., Untenberger R.R. 1958. Carbonaceous free radicals in crude petroleum. Journal of Chemical Physics, 28: 744-745.

[6] Yen T.F., Chilingarian G.V. 1994. Asphaltenes and asphalts 1, Elsevier, New York, 1-379.

[7] Poindexter E.H. 1959. Overhauser effect in asphalt solutions. Journal of Chemical Physics, 31 (6): 1477-1480.

[8] Kirimli H.E., Ovalioglu H., Akay C. 2017. Intermolecular Effects of Fluorocarbons on MC800 Asphaltene and their Characterization. Acta Physica Polonica A, 131 (3): 336-338.

[9] Kirimli H.E., Peksoz A., Ovalioglu H., Yalciner A. 2011. The Effect of Sample Age on Dynamic Nuclear Polarization Parameters in Asphalt Suspensions. Energy Sources, Part A, 33: 604-611.

[10] Abragam A. 1961. The Principles of Nuclear Magnetism. Chap. 8, Oxford University Press, Oxford, 323-353.

[11] Armstrong B.D., Soto P., Shea J.E., Han S. 2009. Overhauser dynamic nuclear polarization and molecular dynamics simulations using pyrroline and piperidine ring nitroxide radicals. Journal of Magnetic Resonanace, 200: 137-141.

[12] Kramer K.D., Müller-Warmuth W. 1964. Über zusammenhänge der Overhauserkernpolarisation mit der molekülbewegung, der frequenz und der relaxation in flüssigkeiten [On the relationship between Overhauser-nuclear polarization, the molecular motion, the frequency and the relaxation in liquids]. Z. Naturforsch, 19a: 375-387.

[13] Ravera E., Luchinat C., Parigi G. 2016. Basic facts and perspectives of Overhauser DNP NMR. Journal of Magnetic Resonance, 264: 78-87.

[14] Levien M., Hiller M., Tkach I., Bennati M., Orlando T. 2020. Nitroxide Derivatives for Dynamic Nuclear Polarization in Liquids: The Role of Rotational Diffusion. Journal of Physical. Chemistry Letters, 11: 1629-1635.

[15] Akay C., Yalciner A. 1995. A new weak field double resonance NMR spectrometer. Z. Naturforsch, 50a: 177-185. 